\title{
Norethisterone induced cerebral venous sinus thrombosis (CVST): a rare case report and review of literature
}

\author{
Ramya $\mathrm{T}^{1 *}$, Prakash $\mathrm{B}^{2}$, Devi $\mathrm{B}^{1}$ \\ ${ }^{1}$ Department of Obstetrics \& Gynaecology, PSG Institute of Medical Sciences \& Research, Coimbatore - 641004, \\ Tamil Nadu, India \\ ${ }^{2}$ Department of Neurology, PSG Institute of Medical Sciences \& Research, Coimbatore - 641004, Tamil Nadu, India
}

Received: 13 November 2013

Accepted: 5 December 2013

\section{*Correspondence:}

Dr. Ramya T,

E-mail: ramya.t2003@gmail.com

(C) 2014 Ramya T et al. This is an open-access article distributed under the terms of the Creative Commons Attribution Non-Commercial License, which permits unrestricted non-commercial use, distribution, and reproduction in any medium, provided the original work is properly cited.

\begin{abstract}
The association between the progestin only pill used for treatment of menstrual disorders and cerebral venous sinus thrombosis (CVST) has rarely been reported in the literature. This report describes a case of cerebral venous thrombosis following intake of norethisterone for menorrhagia secondary to polycystic ovary syndrome in a young woman with undiagnosed underlying hyperhomocysteinemia. A 24 year old married woman presented with acute onset of headache, vomiting and right focal seizures. MRI Cerebral venogram and CT Brain revealed thrombosed anterosuperior segment of superior sagittal sinus and haemorrhagic infarct in right frontoparietal region. The risk factors were acquired hyperhomocysteinemia, polycystic ovary syndrome and norethisterone for menorrhagia. The patient was treated with low molecular weight heparin, followed by warfarin, vitamin $\mathrm{B}_{12}$, vitamin $\mathrm{B}_{6}$ and folic acid. She made a total recovery. Although venous thrombosis is usually linked to the ingestion of estrogen, rather than progestogen, this case illustrates that patients who are prescribed progestogen only pills for gynaecological disorders may develop thrombosis, especially if they have predisposing metabolic disorders.
\end{abstract}

Keywords: Cerebral venous sinus thrombosis, Norethisterone, Polycystic ovary syndrome, Hyperhomocysteinemia

\section{INTRODUCTION}

Cerebral venous sinus thrombosis is a potential life threatening condition that requires rapid diagnosis and urgent treatment. The association between progestin only pill used for the treatment of menstrual disorders and cerebral venous thrombosis has rarely been reported in literature. ${ }^{31-33}$ Rajput $\mathrm{R}$ et al. had documented a case of CVST in a young woman taking norethindrone acetate for menorrhagia who also had acquired hyperhomocysteinemia. ${ }^{32}$ Hitendra Singh et al. had reported a case of norethisterone induced CVST presenting as subarachnoid haemorrhage in a patient of menorrhagia. ${ }^{31}$ The influence of specific types of combined oral contraceptives on the risk of thrombotic events remains the most important safety issue for these products. Several studies showed an increased risk of venous thromboembolism (VTE) in current users of combined oral contraceptives and a decreasing risk by both time of use and decreasing oestrogen dose.

Results on the significance of the type of progestogen differed. Progestogen only products conferred no increased risk of venous thromboembolism, whether taken as low dose norethisterone pills, as desogestrel only pills or in the form of hormone releasing intrauterine devices. The relative risk of VTE from using oral contraceptives with norethisterone, levonorgestrel, desogestrel or gestodene decreased with decreasing oestrogen dose. The risk was higher with oral contraceptives containing the progestogen drospirenone, desogestrel, gestodene than those containing levonorgestrel. 


\section{CASE REPORT}

A 24 year old married woman, a known case of polycystic ovary syndrome presented with two days history of headache, vomiting and one episode of right focal seizures. Her menstrual cycles were irregular with intermittent episodes of heavy bleeding since menarche. She was prescribed norethisterone $5 \mathrm{mg}$ thrice daily for past 50 days which she had stopped only after the onset of symptoms.

No history of previous seizure tendency, head trauma, fever, chest pain, shortness of breath, ataxia, double vision, facial asymmetry, limb weakness or sensory loss was present.

She was married for three years and diagnosed to have polycystic ovarian syndrome a year ago. The couple was trying conception since marriage. They were not under treatment for the same. No history of diabetes, hypertension, CAD - atherosclerotic disease or stroke.

On examination at the time of presentation she was conscious, alert, moving all limbs normally. Vitals were normal. Pupils were $2.5 \mathrm{~mm}$, equally reacting to light, no neck stiffness, deep tendon reflexes were normal, plantar bilateral flexor. Cardio vascular, respiratory and per abdominal examinations were unremarkable.

Routine investigations like haemogram and biochemistry were within the normal range. MRI and MR venogram revealed right frontal lobe focal acute haemorrhage with perifocal oedema and small haemorrhage in left frontal lobe and dural venous thrombosis of anterosuperior segment of superior sagittal sinus. CT brain plain four days later showed area of haemorrhagic infarct in right frontoparietal region and a small area of infarct in left frontal region. Midline shift to left by $6 \mathrm{~mm}$ and effacement of frontal horn of right lateral ventricle.

Thrombophilia profile including ANA, anti-PLP antibodies, factor $\mathrm{V}$ Leiden mutation were also in normal ranges. But serum homocysteine level was raised $(>50 \mathrm{mmol} / \mathrm{L})$. Ultrasound confirmed polycystic ovaries.

Based upon this diagnostic work-up, we made the following diagnosis: Drug induced cerebral venous sinus thrombosis with polycystic ovarian syndrome with hyperhomocysteinemia as an additional risk factor.

Patient was treated with antioedema measures, antiepileptics, low molecular weight heparin followed by oral anticoagulants. The oedema resolved and the patient became asymptomatic. There were no further episodes of haemorrhage and seizures except for few episodes of headache and vomiting. She was discharged 18 days later with oral anticoagulants, anti-epileptics and multivitamins (Vit $\mathrm{B}_{12}$, Vit $\mathrm{B}_{6}$, Folic acid). She was also advised to avoid prothrombotic conditions and to have a planned pregnancy.
One year later on follow up, she was asymptomatic. Oral anticoagulant was stopped. MRI and MR cerebral venogram were repeated. Gliotic area in right frontal cerebral parenchyma was reported with complete recanalization of superior sagittal sinus. Patient was put on long term anti epileptics in view of scar. She was advised to continue multivitamins and to avoid thrombosis provokers.

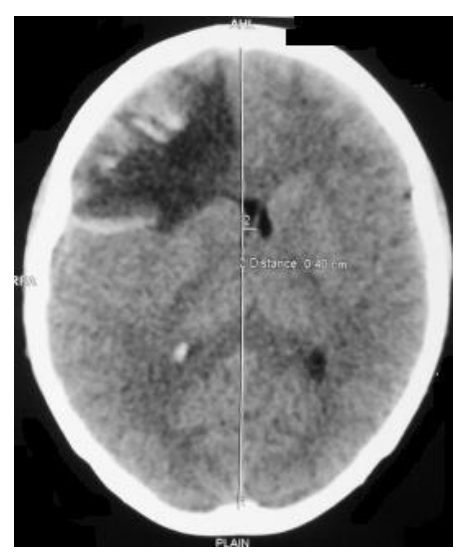

Figure 1: Plain CT of brain showing right frontal haemorrhagic infort with midline shift.

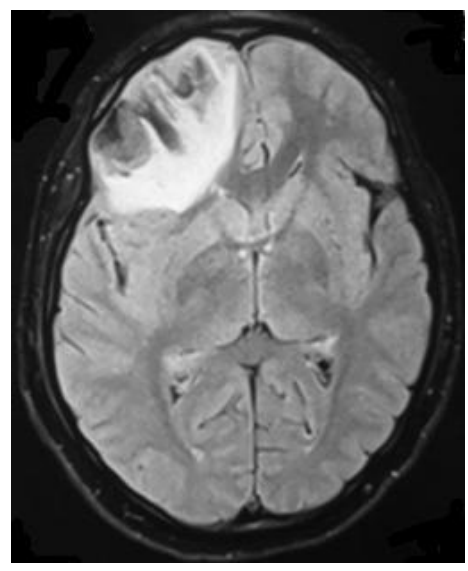

Figure 2: T1 weighted MRI brain showing right frontal hyper intense lesion with haemorrhage.

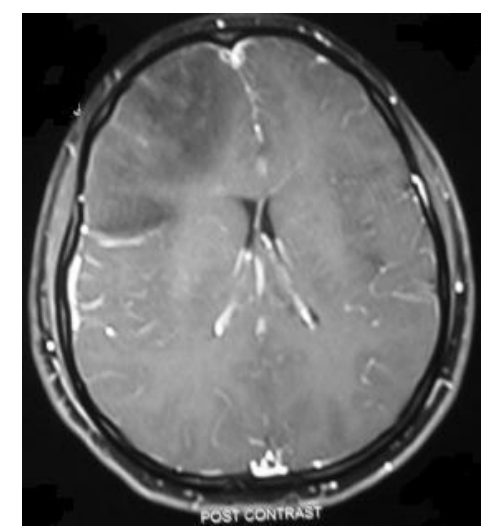

Figure 3: Contrast MRI did not show any enhancement ruling out the possibility of tumour. 


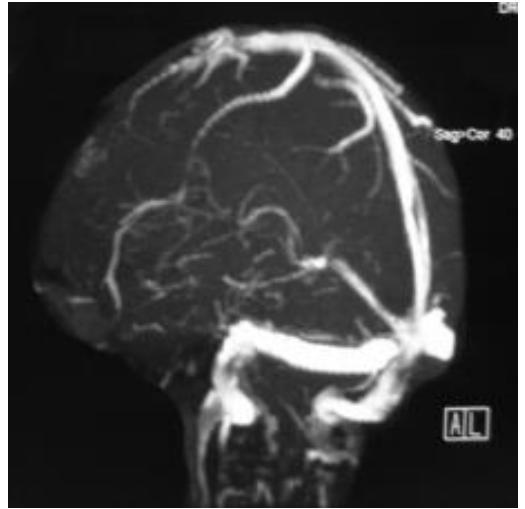

Figure 4: MR venogram showing poor visualization of anterior segment of superior sagittal sinus.

\section{DISCUSSION}

Cerebral venous sinus thrombosis is an uncommon but potentially fatal condition, especially in young women. Common etiologies include hypercoagulable states, dehydration, adjacent infectious processes, oral contraceptives, hormone replacement therapy, pregnancy and puerperium. ${ }^{1}$ CVST was found to be more common in women than men; female to male ratio was 1.29:1. Uniform age distribution was found in men, while $61 \%$ of women were aged 20 - 35 years.

CVST presents as severe headache (the most common symptom). Other features include nausea and vomiting, seizures, decreased level of consciousness to coma, and focal neurological deficits. ${ }^{2}$ Diagnosis is by neuroimaging the thrombosed vessel - the gold standard is the combination of MRI brain with venogram. The mainstay of therapy is anticoagulation and other procedures of recanalisation. ${ }^{3}$

Shortly after the introduction of the first combined contraceptive, a case of venous thrombosis associated with contraceptive use was reported. ${ }^{4}$ Since then, many observational studies have shown that combined oral contraceptives are associated with a two fold to six fold increased risk of venous thrombosis. ${ }^{5-8}$ Despite the low incidence of venous thrombosis-about three per 10,000 woman years-among women of reproductive age, ${ }^{9}$ the effect of combined oral contraceptives on venous thrombosis is large, owing to the fact that many women use oral contraceptives.

Because the oestrogen compound (ethinylestradiol) in combined oral contraceptives was thought to cause the increased risk in thrombosis, the dose of ethinylestradiol was lowered from $150-100 \mu \mathrm{g}$ in the earliest brands to $50 \mu \mathrm{g}$ in the $1960 \mathrm{~s}$ and to $30-35 \mu \mathrm{g}$ and $20 \mu \mathrm{g}$ in the 1970 s. $^{10-12}$ The reduced dose of ethinylestradiol in contraceptives was indeed associated with a reduction in the risk of venous thrombosis. ${ }^{13-17}$ Apart from adjustments in the dose of ethinylestradiol, the progestogen compound was also changed in an effort to reduce the side effects. After the first generation progestogens (that is, norethisterone and lynestrol), new progestogens were developed. These new compounds were called second generation (that is, levonorgestrel) and third generation progestogens (that is, gestodene, desogestrel, norgestimate). ${ }^{4}$ However, users of combined oral contraceptives with third generation progestogens have a higher risk of venous thrombosis than those using second generation progestogens. ${ }^{5-8}$ Other progestogens have been developed after the introduction of third generation progestogens - that is drospirenone (introduced in 2001). The thrombosis risk for contraceptives with drospirenone was found to be higher than for combined oral contraceptives using second generation progestogens. ${ }^{9,10}$

Although the risk of venous thrombosis increased with the dose of ethinylestradiol, this seemed to depend on the progestogen provided. It is unclear why the dose effect of ethinylestradiol might depend on the progestogen. A possibility is that there is a difference in inhibitory effects of the progestogen on the procoagulant effect of ethinylestradiol. Oral contraceptive use increases the levels of factors II, VII, VIII, protein C, and decreases the levels of antithrombin, tissue factor pathway inhibitor, and protein S. Clinical studies have showed that this effect on coagulation factors was more pronounced in desogestrel users than in levonorgestrel users, and limited to combined oral contraceptives. ${ }^{18,19}$

It should be kept in mind that all combined oral contraceptives increase the risk of venous thrombosis, which is not the case for the levonorgestrel intrauterine device. ${ }^{20}$ However, if a woman prefers using combined oral contraceptives, only those with the lowest risk of venous thrombosis should be prescribed, such as levonorgestrel with $30 \mu \mathrm{g}$ of ethinylestradiol.

Homocysteine is a naturally occurring molecule in the body and it is required in several reactions that occur within cells. They result in the formation of cysteine and methionine, which can be further used by the body. If the pathways to either cysteine or methionine are blocked, due to genetic abnormalities of enzymes or deficiencies of cofactors (folic acid, Vit $\mathrm{B}_{12}$, Vit $\mathrm{B}_{6}$ ) then homocysteine levels may rise. Other causes include chronic kidney disease, certain medications, cigarette smoking and alcoholism.

Normal levels are in the range between 5 to 15 micromoles per liter. Elevated levels are associated with atherosclerosis, tendency to excessive blood clotting in the arteries. Hyperhomocysteinemia has been shown to be related to clots in veins (deep vein thrombosis, pulmonary embolism), ${ }^{21,22}$ though the relationship is less strong than that of arterial thrombosis. . $^{23,24,30}$

Mild hyperhomocysteinemia levels are seen in about 5\% to $12 \%$ of the general population. Vitamin supplementation primarily with folic acid, and to a lesser degree with pyridoxine and $\mathrm{VitB}_{12}$ is effective in reducing elevated levels of plasma homocysteine. ${ }^{25,30}$ 
However, it is noteworthy that so far there is no compelling data to support the treatment of hyperhomocysteinemia for the prevention of heart disease or treatment of known heart disease or blood clots. ${ }^{26-29}$

The daily recommended doses are $1 \mathrm{mg}$ of folic acid, $10 \mathrm{mg}$ of $\mathrm{Vit} \mathrm{B}_{6}$, one half milligram of $\mathrm{Vit} \mathrm{B}_{12}$.

\section{CONCLUSION}

Although venous thrombosis is usually linked to the ingestion of estrogen, rather than progestogen, this case illustrates that patients who are prescribed progestogen only pills for gynaecological disorders may develop thrombosis, especially if they have predisposing metabolic disorders.

\section{Funding: No funding sources}

Conflict of interest: None declared

Ethical approval: Not required

\section{REFERENCES}

1. Denise M. Lemke, Lofti Hacein-Bey. Cerebral Venous Sinus Thrombosis. J Neurosci Nurs. 2005;37(5):258-64.

2. Van Gijn J. Cerebral venous thrombosis: Pathogenesis, presentation and prognosis. J R Soc Med. 2002;93:230-3.

3. Baumgartner RW, Studer A, Arnold M. Recanalisation of cerebral venous thrombosis. J Neurolneurosurg Psychiatry. 2003;74:459-61.

4. Jordan W. Pulmonary embolism. Lancet. 1961;278:1146-7.

5. Oral contraception and thrombo-embolic disease. J R Coll Gen Pract. 1967;13:267-79..

6. Inman WH, Vessey MP. Investigation of deaths from pulmonary, coronary, and cerebral thrombosis and embolism in women of child-bearing age. BMJ. 1968;2:193-9.

7. Sartwell PE, Masi AT, Arthes FG et al. Thromboembolism and oral contraceptives: an epidemiologic case-control study. Am J Epidemiol. 1969;90:365-80.

8. Vessey MP, Doll R. Investigation of relation between use of oral contraceptives and thromboembolic disease. A further report. BMJ. 1969;2:651-7.

9. Naess IA, Christiansen SC, Romundstad P et al. J. Incidence and mortality of venous thrombosis: a population-based study. J Thromb Haemost. 2007;5:692-9.

10. Thorogood M, Villard-Mackintosh L. Combined oral contraceptives: risks and benefits. $\mathrm{Br}$ Med Bull. 1993;49:124-39.

11. Wharton C, Blackburn R. Lower dose pills. Population Rep. 1988;16:1-31.

12. Stolley PD, Tonascia JA, Tockman MS et al. Thrombosis with low-estrogen oral contraceptives. Am J Epidemiol. 1975;102:197-208.
13. World Health Organization Collaborative Study of Cardiovascular Disease and Steroid Hormone Contraception. Venous thromboembolic disease and combined oral contraceptives: results of international multicentre case-control study. Lancet. 1995;346:1575-82.

14. Inman WH, Vessey MP, Westerholm B et al. Thromboembolic disease and the steroidal content of oral contraceptives. A report to the Committee on Safety of Drugs. BMJ. 1970;2:203-9.

15. Vessey M, Mant D, Smith A et al. Oral contraceptives and venous thromboembolism: findings in a large prospective study. Br Med J. (Clin Res Ed). 1986;292:526.

16. Lidegaard O, Edstrom B, Kreiner S. Oral contraceptives and venous thromboembolism: a fiveyear national case-control study. Contraception. 2002;65:187-96.

17. Meade TW, Greenberg G, Thompson SG. Progestogens and cardiovascular reactions associated with oral contraceptives and a comparison of the safety of 50- and 30-microgram oestrogen preparations. BMJ. 1980;280:1157-61.

18. Kemmeren JM, Algra A, Meijers JC et al. Effects of second and third generation oral contraceptives and their respective progestagens on the coagulation system in the absence or presence of the factor $\mathrm{V}$ Leiden mutation. Thromb Haemost. 2002;87:199205.

19. Kemmeren JM, Algra A, Meijers JC, et al. Effect of second- and third-generation oral contraceptives on the protein $\mathrm{C}$ system in the absence or presence of the factor VLeiden mutation: a randomized trial. Blood. 2004; 103:927-33.

20. Van Hylckama Vlieg, A, Helmerhorst FM, Rosendaal FR. The risk of deep venous thrombosis associated with injectable depotmedroxyprogesterone acetate contraceptives or a levonorgestrel intrauterine device. Arterioscler Thromb Vasc Biol. 2010;30:2297-300.

21. Kottke-Marchant K, R Green, D Jacobsen et al. High plasma homocysteine: a risk factor for arterial and venous thrombosis in patients with normal coagulation profiles. Clini appl Thromb hemost. 1997;3:239-44.

22. Falcon C, M Cattanco, D panzer et al. High prevalence of hyperhomocysteinemia with juvenile venous thrombosis. Arterioscler thromb. 1994;14:1080-3.

23. Bauer KA. Hypercoagulable states. In: Hoffman R, Benz EJ Jr, Shattil SJ et al. eds. Hematology: Basic Principles and Practice. 3rd ed. New York: Churchill Livingstone; 1995: 1781-1795.

24. Allaart CF, Briet E. Familial venous thrombophilia. In: Bloom AL, Forbes CD, Thomas DP et al. eds. Haemostasis and Thrombosis. 3rd ed. London: Churchill Livingstone; 1994: 1349.

25. Svensson PJ, Dahlback B. Resistance to activated protein $\mathrm{C}$ as a basis for venous thrombosis. N Engl $\mathbf{J}$ Med. 1994;330:517-22. 
26. Koster T, Rosendaal FR, de Ronde $\mathrm{H}$ et al. Venous thrombosis due to poor anticoagulant response to activated protein C: Leiden Thrombophilia Study. Lancet. 1993;342:1503-6.

27. Griffin JH, Evatt B, Wideman C et al. Anticoagulant protein $\mathrm{C}$ pathway defective in majority of thrombophilic patients. Blood. 1993;82:1989-93.

28. Harris JM, Abramson N. Evaluation of recurrent thrombosis and hypercoagulability. Am Fam Physician. 1997;56:1591-6,1601.

29. Gandrille S, Greengard JS, Alhenc-Gelas M, et al. Incidence of activated protein $C$ resistance caused by the ARG 506 GLN mutation in factor $\mathrm{V}$ in 113 unrelated symptomatic protein $\mathrm{C}$-deficient patients. The French Network on the behalf of INSERM. Blood. 1995;86:219-24.

30. Gatt A, Makris M. Hyperhomocysteinemia and venous thrombosis. Semin Hematol. 2007 Apr;44(2):70-6.
31. Hitendra Singh Tanwar, AK Gadpayle. A rare case of drug induced cortical venous sinus thrombosis presenting as subarachnoid haemorrhage in a patient of menorrhagia: A great dilemma in management. JIACM. 2010;11(4):330-5.

32. Rajput R, Dhuan J, Agarwal S. CVST in a young woman taking norethindrone acetate for DUB: a case report and review of literature. J Obstet Gynaecol Can. 2008 Aug;30(8):680-3.

33. Hitosugi M, Kitamira O, Takatsu A. A case of dural sinus thrombosis during the medication of medroxy progesterone acetate. Nihon Hoigaku zasshi. 1997 Dec;51(6):452-6.

DOI: $10.5455 / 2320-1770 . i j r \operatorname{cog} 20140347$

Cite this article as: Ramya T, Prakash B, Devi B. Norethisterone induced cerebral venous sinus thrombosis (CVST): a rare case report and review of literature. Int J Reprod Contracept Obstet Gynecol 2014;3:231-5. 